\title{
EXPERIMENTAL RESEARCHES REGARDING THE ECOLOGICAL DYEING WITH NATURAL EXTRACTS
}

\author{
Budeanu Ramona, Curteza Antonela*, Radu Cezar Doru \\ Technical University "Gheorghe Asachi” of lasi, Faculty of Textiles-Leather and Industrial Management, \\ lasi, Romania , Dimitrie Mangeron Bvl. No.67, 700050 \\ E-mail:ACurteza@gmail.com
}

\begin{abstract}
:
The concept of 'environmental awareness' has recently had a major impact on the textile industry and on the fashion world as well. In this context, the use of natural fibres and the development of natural dyeing processes gradually became important goals of the textile industry. Of all natural textile fibres, hemp is considered to be one of the strongest and most durable. A wide range of natural extracts have been used for natural textile coloration and dyeing. Dyes deriving from natural sources have emerged as an important alternative to synthetic dyes. Ecofriendly, nontoxic, sustainable and renewable natural dyes and pigments have been used for colouring the food substrate, leather, wood, natural fibres and fabrics from the dawn of human history. The purpose of the research is to obtain ecologically coloured fabrics for textiles by using a method of dyeing that relies on natural ingredients extracted from red beet, onion leaves and black tea. The experiments are conducted on three different types of hemp fabrics. This paper presents the results of the studies regarding the dyeing process of hemp fabrics with natural extracts, the colours of the dyed samples inspected with reflectance spectra and the CIE $L^{*} a^{*} b^{*}$ colour space measurements.
\end{abstract}

\section{Keywords:}

Natural, extract, dyes, ecology, colours, analysis, hemp, fabrics

\section{Introduction}

The textile processing industry is well-known for being one of the biggest polluters in the world [5], mainly because it uses large amounts of processed water, chemicals and dyeing products that are harming the environment. Therefore, in order to suppress the negative impact of this particular industrial sector, there are two essential ways of protecting nature: building facilities that are efficient and big enough so as to treat the eliminated water and using eco-friendly dyeing products and chemical substances. [3]

Ecological considerations became a crucial factor in industry as early as the 1980s, when people grew more and more interested in using natural dyes when manufacturing textile products [30]. Even though everyone agrees that the use of artificial dyes harms the workers by facilitating the occurrence of allergies that are visible on the skin and the surrounding environment, as well by damaging the natural balance through contamination, not much has been done so far because such dyes are easily available, cheap and can produce a wide spectrum of colours. [26]

As the world becomes more and more aware that nature must be protected, the research community is putting a lot of work into identifying various ecological solutions for treating and finishing fabrics, as well as into developing technologies that would assure the creation of eco-friendly textile products, including the use of natural fabrics and dyes.
For this purpose, all natural fabrics such as hemp, one of the highest quality fibres with exceptional physical properties, high comfort, excellent durability and ecological manufacturing processes and, at the same time, one of the most environmentally friendly and versatile natural textile plants on Earth, has a promising potential. Also, fabrics made of hemp can be produced in a variety of weights and textures. Hemp not only possesses several excellent properties such as strength, warmth, comfort and durability, it is also considered to be an environmentally friendly plant because it does not require as many pesticides and herbicides to be successfully grown [15].

Dyeing is considered to be an art that goes back to the dawn of humankind. In Europe, dyeing techniques have been developed as early as the Bronze Age. From ancient times, natural dyes have been used for dyeing fabrics and apparel products $[6,10,20]$.

Until the development of artificial dyes, the textile dyeing process was done with the help of colorants and pigments extracted from natural sources, such as plants, roots, stems, bark, leaves, berries and flowers. After the discovery of synthetic colorants, the natural ones were forgotten for quite a while. They were dismissed as being obsolete.

The raw materials used in the fabrication of natural dyes are mostly plant parts: leaves, roots, flowers, tree bark, and seeds $[9,13]$. 
Nature has always been an extremely rich source of visual inspiration, even from early times when primitive man discovered vegetal pigments and the way to use it so as to give colour and life to textile products. At first, the dyeing techniques were rudimentary. The plants were attached to, rubbed against or crushed on the fabric. As man progressed, the dyeing methods and techniques became more and more sophisticated by boiling the fruit and plants when colouring the material $[11,16]$.

The natural pigments, considered to be renewable, biodegradable, eco-friendly and long-lasting, made a comeback as being a viable alternative to the excessive use of artificial colorants (about 10,000,000 tons a year) [5, 11, 16, $25]$, in the context of society being increasingly preoccupied with protecting the environment and staying healthy. As a consequence, the use of natural pigments when dyeing textile fabrics has become a global hot topic.

In textile dyeing, natural dyes extracted from various plants can be used for the coloration of both textile fibres and fabrics. Apart from the fact that all natural dyes have a better biodegradability and are more compatible with the environment, they also have a range of properties such as excellent softness, shininess and aesthetic appeal, aspects that are considered to be the most important attributes in the eyes of the consumers [2].

The technology of producing such pigments varies from the use of aqueous solutions to complicated solvent systems and sophisticated supercritical fluid extraction techniques, depending on the required product and purity. Generally, the fabrication of natural pigments consists of boiling the crushed powder with water and leaving it to steep in cold water [27]. Several researchers noticed that the extraction of natural pigments by inducing cosolvents leads to extracts that are not completely soluble in water [14, 23]. So far, literature and researchers focused on the application of natural dyes on various textile fabrics, mordants and mordanting methods and so on, recording their fastness properties and colorimetric data [17].

All natural dyes are eco-friendly and provide a wide range of beautiful shades with acceptable level of colour fastness $[4,7,12,28]$. Various reports have been favourable to the behaviour and applications of natural dyes on textiles [1, 8, 22, $24,29]$. Natural pigments are considered safe because of their nontoxic, nonallergic and biodegradable nature [19, 25]. Many of the plants used for extracting natural dyes are classified as medicinal plants. Some of them were recently proved to possess remarkable antibacterial properties [21].

Currently, natural dyes are used in textile manufacturing, as well as in other industrial branches: cosmetics, pharmaceutics, paint industries and so on, in order, to prevent the ecological issues caused by synthetic colorants. The art of dying by using natural pigments keeps spreading because it brings beauty and innovation in industry, but it also protects the environment and our health.

\section{Experimental}

\subsection{Materials}

This exploratory study was conducted in order to develop an ecological process of dyeing with natural extracts of red beet, onion leaves and black tea on three different types of hemp fabrics. The material used is $100 \%$ hemp fabric (three different types from TEXFIR, Romania). The following ingredients were used to treat the fabric: sodium hydroxide $38^{\circ} \mathrm{BE}, 33 \%$, Tannex CB, Hydrogen peroxide $35 \%$ and Tanaterge Advance.

- Fabric 1: hemp 100\%, fineness of warp yarn: $\mathrm{Nm}=10 / 2$, fineness of weft yarn: $\mathrm{Nm}=10 / 1$ and specific weight: $276 \mathrm{~g} / \mathrm{m}^{2}$ - Fabric 2: hemp 100\%, fineness of warp yarn: $\mathrm{Nm}=10 / 1$, fineness of weft yarn: $\mathrm{Nm}=10 / 1$ and specific weight: $400 \mathrm{~g} / \mathrm{m}^{2}$ - Fabric 3: hemp $100 \%$, fineness of warp yarn: $\mathrm{Nm}=14 / 1$, fineness of weft yarn: $\mathrm{Nm}=14 / 1$ and specific weight: $250 \mathrm{~g} / \mathrm{m}^{2}$

\subsection{Methods}

\subsubsection{Pretreatment of fabrics (Scouring)}

In order to obtain a high degree of white, the fabric samples were previously treated by scouring and bleaching. The experiments were conducted in the laboratory on a Linitester device. The optimal conditions were: temperature of $98^{\circ} \mathrm{C}$, $1 \mathrm{~h}$ of incubation time, Sodium hydroxide $38^{\circ} \mathrm{BE}, 33 \%$ Tannex CB, $5 \mathrm{ml}$ Hydrogen peroxyde $35 \%$, Tanaterge Advance). After completing the process, the samples were rinsed with water at $90^{\circ} \mathrm{C}$ for 1 hour on Linitester and then rinsed thoroughly with cold water and dried in an oven for 30 minutes at $50^{\circ} \mathrm{C}$.

The scoured material was thoroughly washed with tap water and dried at room temperature. The scoured material was soaked in clean water for 30 minutes prior to dyeing.

\subsubsection{Dyeing Process with natural extracts}

The samples were dyed with extracts (see Figure 1) from red beet, onion leaves and black tea, at 1:40 liquor ratio.

- Red beet: it was cut into small pieces $(3 \mathrm{~kg})$ and put to boil in a dyeing bath with 2 litres of water at a temperature of $150^{\circ} \mathrm{C}$, resulting in 1 litre of dye.

- Onion leaves: 600 grams of dried onion leaves were left to boil for 1 hour in 4 litres of water at $100^{\circ} \mathrm{C}$, thus obtaining 2 litres of dye solution.

- Black tea: 500 grams of black tea was left to boil in about 2.5 litres of water at a temperature of $130^{\circ} \mathrm{C}$ for 50 minutes, resulting 1 litre of dye.

Dyeing additions ( $\mathrm{pH}$ adjustment) were: acetic acid. After dyeing, fabrics were washed at $30^{\circ} \mathrm{C}$, rinsed and dried at room temperature. Figure 1 shows the raw material from which natural pigments are made: (a)red beet , (b) onion leaves and (c) black tea. 


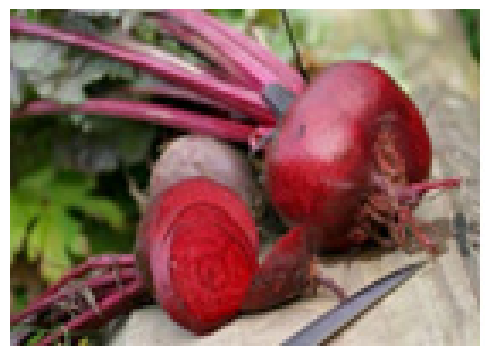

a.

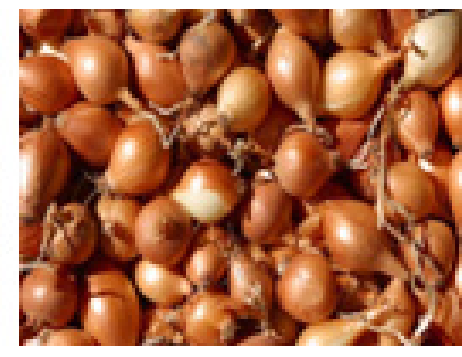

b.

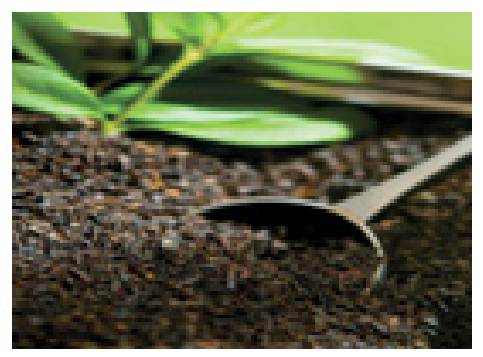

C.

Figure 1. Dyestuff sources: (a) red beet, (b) onion leaves and (c) black tea.

\section{Measurements and analysis}

Figures 2, 3 and 4 illustrate the colour spectrum obtained after dyeing the fabric with natural pigments extracted from red beet, onion leaves and black tea:

The colours corresponding to the first fabric were obtained by applying the following recipes : sample 1: $10 \mathrm{ml}$ red beet extract/l at a liquor ratio of 1:100, for 2 hours; sample 2: $10 \mathrm{ml}$ onion extract/l at a liquor ratio of 1:100, for two hours; sample 3: $7 \mathrm{ml}$ red beet extract/l at a liquor ratio of 1:100, for 1 hour; sample 4: $10 \mathrm{ml}$ onion extract/l at a liquor ratio of 1:100, for 2 hours; sample 5: $10 \mathrm{ml}$ black tea extract/l at a liquor ratio of 1:100, for 2 hours; sample 6: $10 \mathrm{ml}$ black tea extract/l at a liquor ratio of 1:100, for 2 hours; sample 7: $5 \mathrm{ml}$ red beet extract/l at a liquor ratio of 1:100, for 1 hour; sample 8: $10 \mathrm{ml}$ onion extract/l at a liquor ratio of 1:100, for 1 hour; sample 9: $10 \mathrm{ml}$ red beet extract/l at a liquor ratio of $1: 100$, for 2 hours; sample 10: $5 \mathrm{ml}$ red beet extract/l at a liquor ratio of 1:100, for 1 hour; sample 11: $5 \mathrm{ml}$ red beet extract/l at a liquor ratio of 1:100, for 1 hour.

The colours coresponding to the second fabric were obtained by applying the following recipes : sample 1: $7 \mathrm{ml}$ red beet extract/l at a liquor ratio of 1:100, for 1 hour; sample 2: $10 \mathrm{ml}$ red beet extract/l at a liquor ratio of 1:100, for 2 hours; sample 3: $5 \mathrm{ml}$ red beet extract/l at a liquor ratio of 1:100, for 1 hour; sample 4: $10 \mathrm{ml}$ onion extract/l at a liquor ratio of 1:100, for 1 hour; sample 5: $10 \mathrm{ml}$ onion extract/l at a liquor ratio of 1:100, for 1 hour; sample 6: $5 \mathrm{ml}$ red beet extract/l at a liquor ratio of
1:100, for 1 hour; sample 7: $10 \mathrm{ml}$ black tea/l at a liquor ratio of 1:100, for 2 hours; sample 8: $10 \mathrm{ml}$ black tea extract/l at a liquor ratio of 1:100, for 1 hour; sample 9: $10 \mathrm{ml}$ onion extract/l at a liquor ratio of 1:100, for 2 hours; sample 10: $7 \mathrm{ml}$ red beet extract/l at a liquor ratio of 1:100, for 1 hour;

The colours corresponding to the third fabric were obtained by applying the following recipes: sample 1: $5 \mathrm{ml}$ black tea/l at a liquor ratio of 1:100, for 1 hour; sample 2: $7 \mathrm{ml}$ black tea/l at a liquor ratio of 1:100, for 1 hour; sample 3: $10 \mathrm{ml}$ red beet extract/l at a liquor ratio of 1:100, for 2 hours; sample 4: $7 \mathrm{ml}$ onion extract/l at a liquor ratio of $1: 100$, for 1 hour; sample 5: $10 \mathrm{ml}$ onion extract/l at a liquor ratio of $1: 100$, for 1 hour; sample 6: $7 \mathrm{ml}$ red beet extract/l at a liquor ratio of $1: 100$, for 1 hour; sample 7: $5 \mathrm{ml}$ onion extract/l at a liquor ratio of 1:100, for 1 hour; sample 8: $10 \mathrm{ml}$ onion extract/l at a liquor ratio of 1:100, for 2 hours; sample 9: $5 \mathrm{ml}$ onion extract/l at a ratio of 1:100, for 1 hour; sample 10: $5 \mathrm{ml}$ red beet extract/l at a liquor ratio of 1:100, for 1 hour;

\subsection{Measurement of Colours}

The Colour strength (K/S) values for each sample were obtained by measuring the reflectance of the dyed samples using the instrument DATACOLOR Spectroflash 300, spectrophotometer under illuminant D65, using $10^{\circ}$ Standard observer for each dyed samples (figures 5, 6 and 7). The colour strength of the dyed fabric samples, in terms of the K/S values, was obtained by using the Kubelka Munk equation [10, 18]

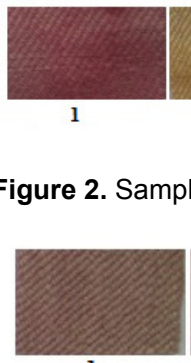

1

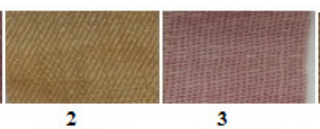

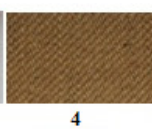

4

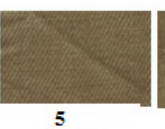

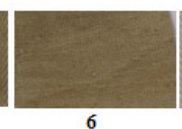

6
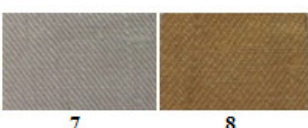

8

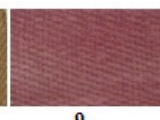

9

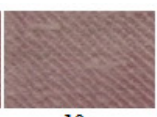

10

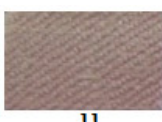

11

Figure 3. Samples hemp fabric 2 after dyeing.
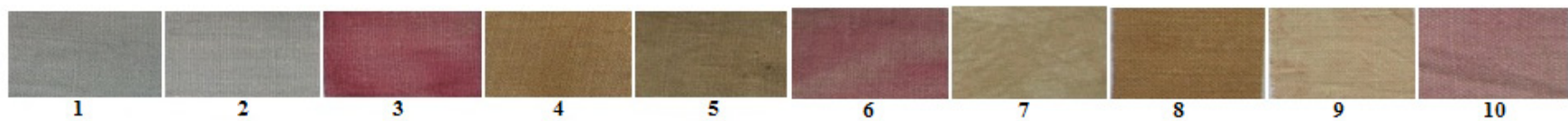

Figure 4. Samples hemp fabric 3 after dyeing 


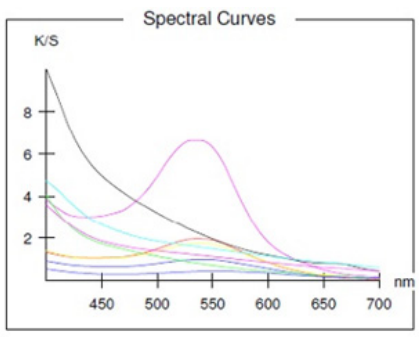

Labels
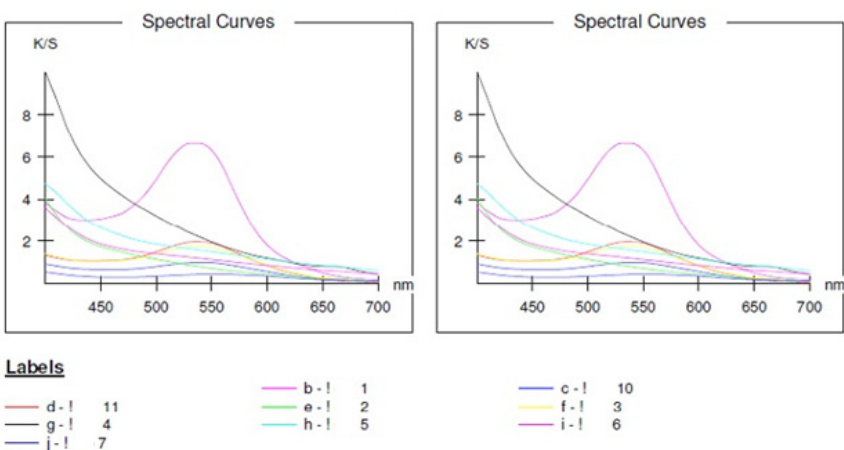

$\begin{array}{ll}0.1 & 10 \\ -i \cdot 1 & 3 \\ -i \cdot 1 & 6\end{array}$

Figure 5. Spectral curves for Fabric 1.
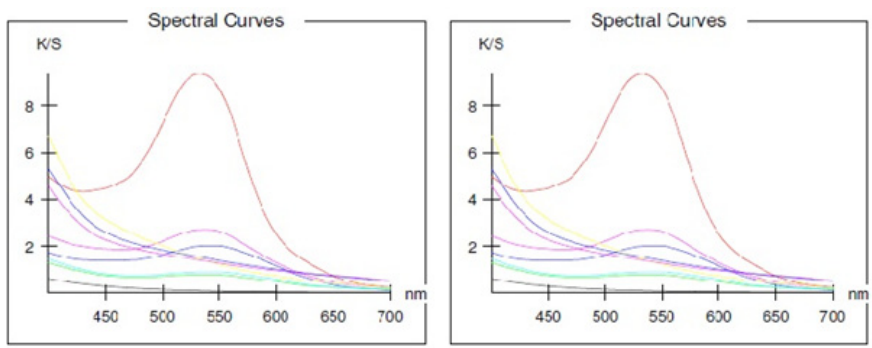

Labels

$\begin{array}{rr}\mathrm{d}-1 & 2 \\ \mathrm{~g}-1 & 5 \\ \mathrm{j}-1 & 8\end{array}$

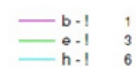

$\begin{array}{rl}\mathrm{e}-1 & 10 \\ \mathrm{i}-1 & 4 \\ -\mathrm{i} .1 & 7\end{array}$

Figure 6. Spectral curves for Fabric 2.
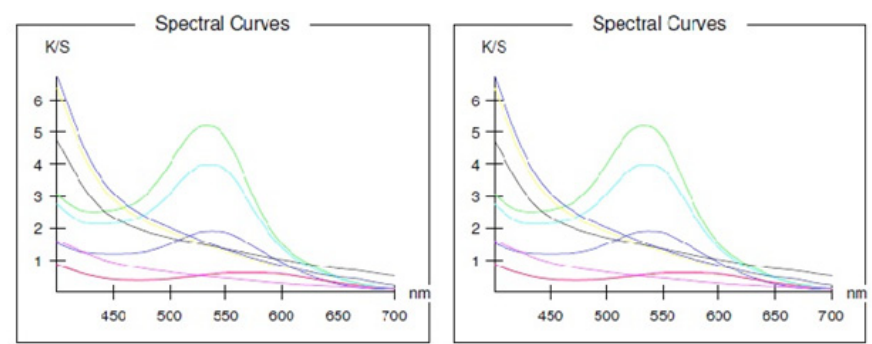

Labels

$\begin{array}{ll}\mathrm{d}-1 & 2 \\ \mathrm{~g} \cdot \mathrm{l} & 5 \\ \mathrm{j} \cdot: & 8\end{array}$

\begin{tabular}{r|r}
$\mathrm{b}-1$ & 1 \\
\hline $\mathrm{e}-1$ & 3 \\
$\mathrm{n}-1$ & 6
\end{tabular}

$\begin{array}{rl}c-1 & 10 \\ -\mathrm{f}=1 & 4 \\ -\mathrm{i} .1 & 7\end{array}$

Figure 7. Spectral curves for Fabric 3.

$$
F(R)=(1-R)^{2} / 2 R=K / S
$$

Where: $K$ is the absorption coefficient and $S$ is the scattering coefficient for a colorant at a specific wavelength; $R$ is the fractional reflectance value of the dye on the substrate at the $\lambda$ max. The $K / S$ value at $\lambda$ max is directly proportional to the concentration of dye on the substrate using the instrument DATACOLOR Spectroflash 300.

The colours are given according to the CIE L*a* $\mathrm{b}^{*}$ coordinates, as specified by the International Commission on Illumination with $L^{*}$ corresponding to brightness $(100=$ white, $0=$ black $), a^{*}$ to the red- green coordinate (positive sign $=$ red, negative sign = green) and $b^{*}$ to the yellow-blue coordinate (positive sign = yellow, negative sign bright red to soft lilac and pink based on carmine, it was = blue).

Tables 1, 2 and 3 illustrate the CIE lab colour range of the analysed fabrics.

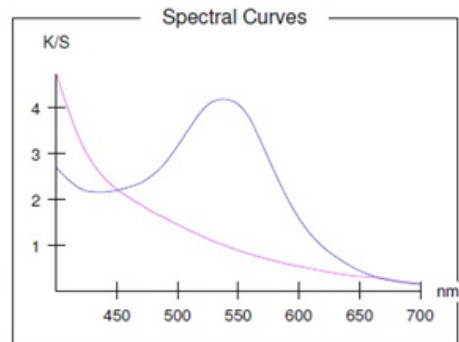

Labels
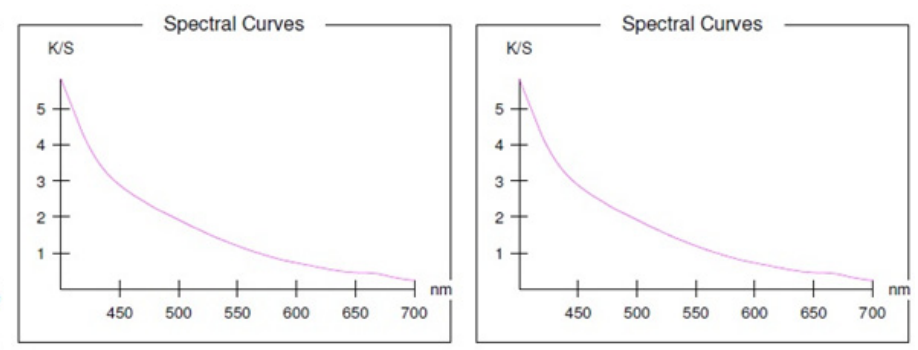

Labels
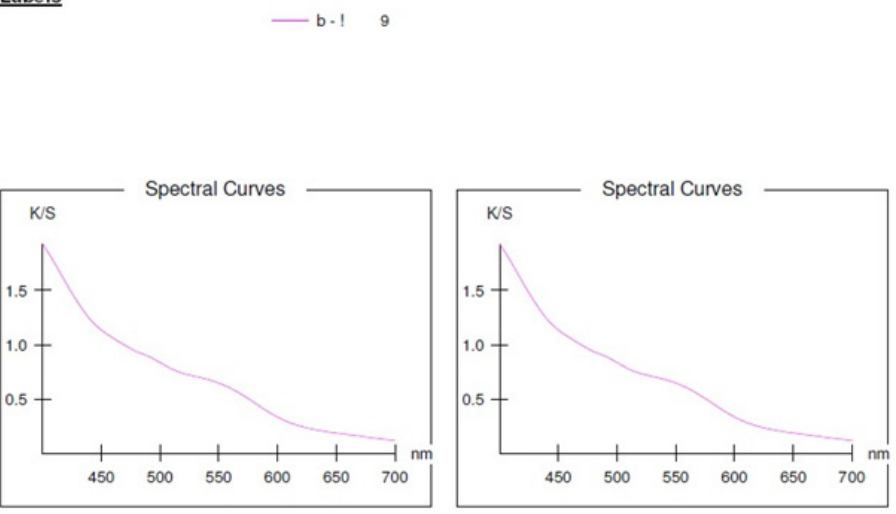

Labels

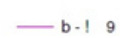

\section{Results and discussion}

After assessing all the samples belonging to the first fabric and considering the variety of colours displayed in Figure 5, it can be observed that samples 1 and 10 have the most intense colours, followed by samples 9 and 8 . The colour intensity of the other samples was ranked according to the lightness factor after the process of absorption from the visible spectrum done through the chromophores belonging to the used natural pigments.

By analysing the spectral curves of the second fabric in Figure 6 and observing the K/S values in concordance with the Kubelka Munk equation, the highest values were obtained for samples 2 and 10. The other values were ranked according to their degree of adhesion to the cellulose material and the luminance factor.

When it comes to the third fabric illustrated in Figure 7, it is obvious that the colours corresponding to samples $\mathbf{6}$ and $\mathbf{3}$ are the most intense. Sample 6 has the highest colour intensity. 
Table 1. CIE lab colour range for fabric 1.

\begin{tabular}{|c|c|c|c|c|c|c|c|c|c|c|}
\hline Fabric & Dye & Batch & $\mathrm{DE}^{*}$ & $D^{*}$ & $\mathrm{Da}^{*}$ & $\mathrm{Db}^{*}$ & $D c^{*}$ & $\mathrm{DH}^{*}$ & Colour & Batch is \\
\hline \multirow{3}{*}{1.} & \multirow{3}{*}{$\begin{array}{l}\text { Red } \\
\text { beet }\end{array}$} & $\mathrm{D} 65 / 10$ & 10.456 & -7.420 & 7.126 & -1.863 & 7.127 & -1.862 & & Darker redder less yellow \\
\hline & & $\mathrm{A} / 10$ & 9.306 & -6.594 & 6.564 & -0.163 & 6.371 & -1.589 & & Darker redder less yellow \\
\hline & & $\mathrm{F} 11 / 10$ & 9.849 & -7.268 & 6.402 & -1.786 & 6.333 & -2.018 & & Darker redder less yellow \\
\hline \multirow{3}{*}{2.} & \multirow{3}{*}{$\begin{array}{l}\text { Onion } \\
\text { leaves }\end{array}$} & $\mathrm{D} 65 / 10$ & 11.321 & 10.562 & -1393 & 3.829 & 2.992 & 2.766 & & Lighter less red yellow \\
\hline & & $\mathrm{A} / 10$ & 11.194 & 10.619 & -0.549 & 3.499 & 2.821 & 2.142 & & Lighter less red yellow \\
\hline & & $\mathrm{F} 11 / 10$ & 11.569 & 10.698 & -1.287 & 4.212 & 3.521 & 2.645 & & Lighter less red yellow \\
\hline \multirow{3}{*}{3.} & \multirow{3}{*}{$\begin{array}{l}\text { Red } \\
\text { beet }\end{array}$} & $\mathrm{D} 65 / 10$ & 9.817 & 8.091 & -4.520 & -3.236 & -4.378 & -3.427 & & Lighter less red less yellow \\
\hline & & $\mathrm{A} / 10$ & 9.694 & 7.317 & -4.284 & -4.699 & -4.999 & -3.930 & & Lighter less red less yellow \\
\hline & & $\mathrm{F} 11 / 10$ & 9.669 & 7.556 & -4.427 & -4.099 & -4.332 & -4.200 & & Lighter less red less yellow \\
\hline \multirow{3}{*}{4.} & \multirow{3}{*}{$\begin{array}{l}\text { Onion } \\
\text { leaves }\end{array}$} & $\mathrm{D} 65 / 10$ & 6.769 & -3.920 & 0.504 & 5.495 & 5.222 & 1.782 & & Darker redder yellow \\
\hline & & $\mathrm{A} / 10$ & 6.733 & -3.641 & 0.801 & 5.607 & 5.309 & 1.973 & & Darker redder yellow \\
\hline & & $\mathrm{F} 11 / 10$ & 7.139 & -3.674 & 0.358 & 6.110 & 5.836 & 1.845 & & Darker redder yellow \\
\hline \multirow{3}{*}{5.} & \multirow{3}{*}{$\begin{array}{c}\text { Black } \\
\text { tea }\end{array}$} & $\mathrm{D} 65 / 10$ & 3.555 & 3.075 & -1.734 & 0.417 & -0.114 & 1.780 & & Lighter less red yellow \\
\hline & & $\mathrm{A} / 10$ & 3.168 & 2.908 & -1.255 & -0.071 & -0.615 & 1.096 & & Lighter less red \\
\hline & & $\mathrm{F} 11 / 10$ & 3.350 & 2.990 & -1.446 & 0.439 & 0.015 & 1.511 & & Lighter less red yellow \\
\hline \multirow{3}{*}{6.} & \multirow{3}{*}{$\begin{array}{c}\text { Black } \\
\text { tea }\end{array}$} & $\mathrm{D} 65 / 10$ & 7.567 & 7.376 & -1.405 & -0.941 & -1.338 & 1.034 & & Lighter less red less yellow \\
\hline & & $\mathrm{A} / 10$ & 7.398 & 7.182 & -1.145 & -1.357 & -1.730 & 0.401 & & Lighter less red less yellow \\
\hline & & $\mathrm{F} 11 / 10$ & 7.460 & 7.278 & -1.244 & -1.067 & -1.389 & 0.869 & & Lighter less red less yellow \\
\hline \multirow{3}{*}{7.} & \multirow{3}{*}{$\begin{array}{l}\text { Red } \\
\text { beet }\end{array}$} & $\mathrm{D} 65 / 10$ & 15.323 & 13.740 & -1.572 & -6.597 & -1.902 & -6.510 & & Lighter less red less yellow \\
\hline & & $\mathrm{A} / 10$ & 15.270 & 13.099 & -2.759 & -7.346 & -3.686 & -6.928 & & Lighter less red less yellow \\
\hline & & $\mathrm{F} 11 / 10$ & 15.444 & 13.312 & -1.702 & -7.643 & -2.148 & -7.530 & & Lighter less red less yellow \\
\hline \multirow{3}{*}{8.} & \multirow{3}{*}{$\begin{array}{l}\text { Onion } \\
\text { leaves }\end{array}$} & $\mathrm{D} 65 / 10$ & 8.941 & 7.515 & -0.569 & 4.811 & 4.196 & 2.421 & & Lighter less red yellow \\
\hline & & $\mathrm{A} / 10$ & 9.038 & 7.700 & 0.221 & 4.727 & 4.263 & 2.054 & & Lighter redder yellow \\
\hline & & $\mathrm{F} 11 / 10$ & 9.402 & 7.723 & -0.628 & 5.325 & 4.781 & 2.429 & & Lighter less red yellow \\
\hline \multirow{3}{*}{9.} & \multirow{3}{*}{$\begin{array}{l}\text { Red } \\
\text { beet }\end{array}$} & $\mathrm{D} 65 / 10$ & 4.963 & -3.057 & 2.038 & -3.336 & 2.148 & -3.266 & & Darker redder less yellow \\
\hline & & $\mathrm{A} / 10$ & 4.766 & -2.992 & 2.067 & -3.081 & 1.476 & -3.404 & & Darker redder less yellow \\
\hline & & $\mathrm{F} 11 / 10$ & 5.283 & -3.265 & 1.647 & -3.813 & 1.671 & -3.803 & & Darker redder less yellow \\
\hline \multirow{3}{*}{10.} & \multirow{3}{*}{$\begin{array}{l}\text { Red } \\
\text { beet }\end{array}$} & $\mathrm{D} 65 / 10$ & 17.941 & 15.143 & -9.293 & -2.489 & -9.207 & -2.791 & & Lighter less red less yellow \\
\hline & & $A / 10$ & 17.279 & 13.823 & -9.028 & -5.099 & -9.759 & -3.502 & & Lighter less red less yellow \\
\hline & & $\mathrm{F} 11 / 10$ & 17.289 & 14.511 & -8.762 & -3.402 & -8.721 & -3.505 & & Lighter less red less yellow \\
\hline \multirow{3}{*}{11.} & \multirow{3}{*}{$\begin{array}{l}\text { Red } \\
\text { beet }\end{array}$} & $\mathrm{D} 65 / 10$ & 8.627 & 7.390 & -1.572 & -4.165 & -1.324 & -4.250 & & Lighter less red less yellow \\
\hline & & $A / 10$ & 8.661 & 6.915 & -1.594 & -4.965 & -2.329 & -4.665 & & Lighter less red less yellow \\
\hline & & $\mathrm{F} 11 / 10$ & 8.657 & 6.905 & -1.595 & -4.972 & -1.401 & -5.030 & & Lighter less red less yellow \\
\hline
\end{tabular}


Table 2. CIE lab colour range for fabric 2.

\begin{tabular}{|c|c|c|c|c|c|c|c|c|c|c|}
\hline Fabric & Dye & Batch & $\mathrm{DE}^{*}$ & $\mathrm{DL}^{*}$ & $\mathbf{D a}^{*}$ & $\mathrm{Db}^{*}$ & $\mathrm{Dc}^{*}$ & $\mathrm{DH}^{*}$ & Colour & Batch is \\
\hline \multirow{3}{*}{1.} & \multirow{3}{*}{$\begin{array}{l}\text { Red } \\
\text { beet }\end{array}$} & $\mathrm{D} 65 / 10$ & 4.786 & 1.631 & -4.499 & 0.044 & -4.492 & 0.246 & & Lighter less red \\
\hline & & $\mathrm{A} / 10$ & 4.130 & 1.081 & -3.781 & -1.260 & -3.974 & -0.311 & & Lighter less red less yellow \\
\hline & & F11/10 & 4.280 & 1.294 & -4.071 & -0.271 & -4.079 & 0.063 & & Lighter less red less yellow \\
\hline \multirow{3}{*}{2.} & \multirow{3}{*}{$\begin{array}{l}\text { Red } \\
\text { beet }\end{array}$} & $\mathrm{D} 65 / 10$ & 13.912 & -12.072 & 6.897 & -0.476 & 6.883 & -0.650 & & Darker redder less yellow \\
\hline & & $\mathrm{A} / 10$ & 12.895 & -11.157 & 6.312 & 1.405 & 6.464 & -0.180 & & Darker redder yellow \\
\hline & & F11/10 & 13.161 & -11.871 & 5.675 & -0.274 & 5.645 & -0.649 & & Darker redder less yellow \\
\hline \multirow{3}{*}{3.} & \multirow{3}{*}{$\begin{array}{l}\text { Red } \\
\text { beet }\end{array}$} & $\mathrm{D} 65 / 10$ & 7.659 & 7.243 & 2.315 & 0.910 & 2.459 & -0.378 & & Lighter redder yellow \\
\hline & & $\mathrm{A} / 10$ & 8.183 & 7.575 & 2.733 & 1.454 & 3.094 & -0.098 & & Lighter redder yellow \\
\hline & & F11/10 & 7.822 & 7.358 & 2.409 & 1.117 & 2.635 & -0.329 & & Lighter redder yellow \\
\hline \multirow{3}{*}{4.} & \multirow{3}{*}{$\begin{array}{l}\text { Onion } \\
\text { leaves }\end{array}$} & D65/10 & 7.184 & 3.327 & 0.786 & 6.319 & 6.092 & 1.853 & & Lighter redder yellow \\
\hline & & $\mathrm{A} / 10$ & 7.673 & 3.717 & 1.564 & 6.528 & 6.476 & 1.768 & & Lighter redder yellow \\
\hline & & F11/10 & 7.957 & 3.625 & 0.586 & 7.059 & 6.807 & 1.958 & & Lighter redder yellow \\
\hline \multirow{3}{*}{5.} & \multirow{3}{*}{$\begin{array}{l}\text { Onion } \\
\text { leaves }\end{array}$} & D65/10 & 33.420 & 35.521 & -7.625 & -1.084 & -3.220 & 6.996 & & Lighter less red less yellow \\
\hline & & $\mathrm{A} / 10$ & 32.574 & 31.648 & -7.119 & -2.967 & -5.642 & 5.258 & & Lighter less red less yellow \\
\hline & & $\mathrm{F} 11 / 10$ & 32.961 & 32.265 & -6.630 & -1.209 & -2.930 & 6.069 & & Lighter less red less yellow \\
\hline \multirow{3}{*}{6.} & \multirow{3}{*}{$\begin{array}{l}\text { Red } \\
\text { beet }\end{array}$} & $\mathrm{D} 65 / 10$ & 6.038 & 5.292 & 2.901 & -0.206 & 2.511 & -1.468 & & Lighter redder less yellow \\
\hline & & $\mathrm{A} / 10$ & 6.581 & 5.625 & 3.395 & 0.368 & 3.194 & -1.207 & & Lighter redder yellow \\
\hline & & F11/10 & 6.106 & 5.327 & 2.981 & -0.160 & 2.556 & -1.543 & & Lighter redder less yellow \\
\hline \multirow{3}{*}{7.} & \multirow{3}{*}{$\begin{array}{c}\text { Black } \\
\text { tea }\end{array}$} & $D 65 / 10$ & 5.651 & 5.495 & -1.058 & 0.788 & 0.419 & 1.251 & & Lighter less red yellow \\
\hline & & $\mathrm{A} / 10$ & 5.507 & 5.428 & -0.773 & 0.524 & 0.127 & 0.925 & & Lighter less red yellow \\
\hline & & $\mathrm{F} 11 / 10$ & 5.647 & 5.499 & -0.957 & 0.856 & 0.541 & 1.164 & & Lighter less red yellow \\
\hline \multirow{3}{*}{8.} & \multirow{3}{*}{$\begin{array}{c}\text { Black } \\
\text { tea }\end{array}$} & $\mathrm{D} 65 / 10$ & 4.914 & 4.378 & -0.324 & 2.208 & 1.989 & 1.012 & & Lighter less red yellow \\
\hline & & $\mathrm{A} / 10$ & 4.950 & 4.469 & 0.285 & 2.109 & 2.012 & 0.694 & & Lighter redder yellow \\
\hline & & F11/10 & 5.086 & 4.441 & -0.251 & 2.465 & 2.280 & 0.970 & & Lighter less red yellow \\
\hline \multirow{3}{*}{9.} & \multirow{3}{*}{$\begin{array}{l}\text { Onion } \\
\text { leaves }\end{array}$} & $\mathrm{D} 65 / 10$ & 5.575 & 3.397 & -0.080 & 4.419 & 4.007 & 1.867 & & Lighter yellow \\
\hline & & $\mathrm{A} / 10$ & 5.722 & 3.601 & 0.452 & 4.424 & 4.096 & 1.732 & & Lighter redder yellow \\
\hline & & F11/10 & 6.105 & 3.603 & -0.111 & 4.927 & 4.565 & 1.858 & & Lighter less red yellow \\
\hline \multirow{3}{*}{10.} & \multirow{3}{*}{$\begin{array}{l}\text { Red } \\
\text { beet }\end{array}$} & $\mathrm{D} 65 / 10$ & 8.643 & 5.086 & -6.659 & -2.117 & -6.625 & -2.222 & & Lighter less red less yellow \\
\hline & & $\mathrm{A} / 10$ & 8.156 & 4.143 & -5.767 & -4.013 & -6.412 & -2.870 & & Lighter less red less yellow \\
\hline & & $\mathrm{F} 11 / 10$ & 8.518 & 4.490 & -6.602 & -2.968 & -6.620 & -2.928 & & Lighter less red less yellow \\
\hline
\end{tabular}


Table 3. CIE lab colour range for fabric 1.

\begin{tabular}{|c|c|c|c|c|c|c|c|c|c|c|}
\hline Fabric & Dye & Batch & $\mathrm{DE}^{*}$ & $\mathrm{DL}^{*}$ & $\mathrm{Da}^{*}$ & $\mathbf{D b}^{*}$ & $\mathrm{Dc}^{*}$ & $\mathrm{DH}^{*}$ & Colour & Batch is \\
\hline \multirow{3}{*}{1.} & \multirow{3}{*}{$\begin{array}{c}\text { Black } \\
\text { tea }\end{array}$} & $\mathrm{D} 65 / 10$ & 12.999 & 9.238 & -4.704 & -7.843 & -3.037 & -8.627 & & Lighter less red less yellow \\
\hline & & $\mathrm{A} / 10$ & 13.736 & 8.157 & -5.442 & -9.620 & -4.447 & -10.119 & & Lighter less red less yellow \\
\hline & & $\mathrm{F} 11 / 10$ & 13.440 & 8.425 & -4.689 & -9.364 & -2.869 & -10.072 & & Lighter less red less yellow \\
\hline \multirow{3}{*}{2.} & \multirow{3}{*}{$\begin{array}{c}\text { Black } \\
\text { tea }\end{array}$} & $\mathrm{D} 65 / 10$ & 13.123 & 9.762 & -5.540 & -6.800 & -4.282 & -7.654 & & Lighter less red less yellow \\
\hline & & $\mathrm{A} / 10$ & 13.778 & 8.656 & -6.301 & -8.672 & -5.716 & -9.068 & & Lighter less red less yellow \\
\hline & & $\mathrm{F} 11 / 10$ & 13.316 & 9.013 & -5.429 & -8.161 & -4.266 & -8.825 & & Lighter less red less yellow \\
\hline \multirow{3}{*}{3.} & \multirow{3}{*}{$\begin{array}{l}\text { Red } \\
\text { beet }\end{array}$} & $\mathrm{D} 65 / 10$ & 7.165 & -4.503 & 5.338 & -1.602 & 5.332 & -1.624 & & Darker redder less yellow \\
\hline & & $\mathrm{A} / 10$ & 6.099 & -3.909 & 4.671 & -0.311 & 4.485 & -1.341 & & Darker redder less yellow \\
\hline & & $\mathrm{F} 11 / 10$ & 6.758 & -4.445 & 4.822 & -1.632 & 4.753 & -1.824 & & Darker redder less yellow \\
\hline \multirow{3}{*}{4.} & \multirow{3}{*}{$\begin{array}{l}\text { Onion } \\
\text { leaves }\end{array}$} & $\mathrm{D} 65 / 10$ & 4.239 & 2.532 & -0.775 & 3.310 & 2.720 & 2.039 & & Lighter less red yellow \\
\hline & & $\mathrm{A} / 10$ & 3.957 & 2.613 & 0.141 & 2.969 & 2.661 & 1.324 & & Lighter redder yellow \\
\hline & & $\mathrm{F} 11 / 10$ & 4.617 & 2.594 & -0.727 & 3.749 & 3.251 & 2.003 & & Lighter less red yellow \\
\hline \multirow{3}{*}{5.} & \multirow{3}{*}{$\begin{array}{c}\text { Black } \\
\text { tea }\end{array}$} & $\mathrm{D} 65 / 10$ & 4.756 & 4.605 & -1.159 & 0.264 & -0.112 & 1.183 & & Lighter less red yellow \\
\hline & & $\mathrm{A} / 10$ & 4.562 & 4.500 & -0.745 & -0.089 & -0.415 & 0.625 & & Lighter less red \\
\hline & & $\mathrm{F} 11 / 10$ & 4.656 & 4.548 & -0.966 & 0.248 & -0.048 & 0.997 & & Lighter less red yellow \\
\hline \multirow{3}{*}{6.} & \multirow{3}{*}{$\begin{array}{l}\text { Red } \\
\text { beet }\end{array}$} & $\mathrm{D} 65 / 10$ & 3.652 & -2.006 & 2.281 & -2.028 & 2.292 & -2.015 & & Darker redder less yellow \\
\hline & & $\mathrm{A} / 10$ & 3.238 & -1.840 & 2.095 & -1.647 & 1.707 & -2.046 & & Darker redder less yellow \\
\hline & & $\mathrm{F} 11 / 10$ & 3.806 & -2.100 & 2.221 & -2.269 & 2.157 & -2.329 & & Darker redder less yellow \\
\hline \multirow{3}{*}{7.} & \multirow{3}{*}{$\begin{array}{c}\text { Black } \\
\text { tea }\end{array}$} & $\mathrm{D} 65 / 10$ & 17.149 & 16.456 & -4.341 & -2.113 & -3.574 & 3.245 & & Lighter less red less yellow \\
\hline & & $\mathrm{A} / 10$ & 16.704 & 15.879 & -4.040 & -3.252 & -4.776 & 2.021 & & Lighter less red less yellow \\
\hline & & $\mathrm{F} 11 / 10$ & 16.790 & 16.258 & -3.511 & -2.295 & -3.351 & 2.523 & & Lighter less red less yellow \\
\hline \multirow{3}{*}{8.} & \multirow{3}{*}{$\begin{array}{l}\text { Onion } \\
\text { leaves }\end{array}$} & $\mathrm{D} 65 / 10$ & 4.185 & 1.840 & -0.503 & 3.725 & 3.205 & 1.963 & & Lighter less red yellow \\
\hline & & $\mathrm{A} / 10$ & 3.998 & 1.968 & 0.388 & 3.459 & 3.209 & 1.346 & & Lighter redder yellow \\
\hline & & $\mathrm{F} 11 / 10$ & 4.656 & 1.926 & -0.473 & 4.212 & 3.771 & 1.935 & & Lighter less red yellow \\
\hline \multirow{3}{*}{9.} & \multirow{3}{*}{$\begin{array}{l}\text { Onion } \\
\text { leaves }\end{array}$} & $\mathrm{D} 65 / 10$ & 13.372 & 13.140 & -0.103 & -2.478 & -2.241 & -1.063 & & Lighter less red less yellow \\
\hline & & $\mathrm{A} / 10$ & 13.299 & 13.021 & 0.408 & -2.677 & -2.035 & -1.786 & & Lighter redder less yellow \\
\hline & & $\mathrm{F} 11 / 10$ & 13.367 & 13.066 & 1.175 & -2.563 & -1.802 & -2.169 & & Lighter redder less yellow \\
\hline \multirow{3}{*}{10.} & \multirow{3}{*}{$\begin{array}{l}\text { Red } \\
\text { beet }\end{array}$} & $\mathrm{D} 65 / 10$ & 8.413 & 6.835 & -4.246 & -2.454 & -4.192 & -2.545 & & Lighter less red less yellow \\
\hline & & $\mathrm{A} / 10$ & 8.160 & 6.154 & -3.781 & -3.796 & -4.415 & -3.035 & & Lighter less red less yellow \\
\hline & & $\mathrm{F} 11 / 10$ & 8.226 & 6.320 & -4.166 & -3.221 & -4.171 & -3.214 & & Lighter less red less yellow \\
\hline
\end{tabular}


Both colours were obtained after dyeing the fabric with natural pigments extracted from red beet.

The colour intensity is directly proportional with the quantity of reflected light. When it comes to the group of tests conducted on the first fabric and displayed in Figure 5, the highest chromatic intensities are reached when dyeing the fabric with red beet extract, followed by the black tea and onion extracts. The same ranking is maintained for the second fabric presented in Figure 6. In the case of the third fabric (Figure 7), the highest chromatic intensities were obtained by using the red beet extract, like in the previous cases, the only difference being that the gap between the chromatic intensities is more accentuated.

\section{Conclusions}

The natural pigments used in the experimental study that we conducted have a good colouring capacity, thus being able to obtain bright nuances and go from dull to averagely intense colours. The dyeing factors, especially the quantity of extract that was used, determine the intensity of the obtained colours.

By using these three natural sources (red beet, black tea and onion) we were able to carry out an efficient and eco-friendly dyeing process that covered the necessary colour spectrum for each fabric.

Natural pigments have a rich history and are able to provide beautiful colours; they are eco-friendly and have a positive impact on our health. Still, they have to compete against artificial colorants that are cheaper, easier to obtain and able to produce a wider range of colours and nuances.

According to the literature, many researchers are preoccupied with the aspects, the issues and the perspectives of applying natural dyes at an industrial scale.

\section{References}

[1] Adeel, S., Ali, S., Bhatti, A., Zsila, F. (2009). Dyeing of cotton fabric using pomegranate (Punica granatum) aqueous extract, Asian Journal of Chemistry, vol. 21, no.5, pages 3493-3499.

[2] Al-Amoudi, E.S., Osman, E. M. (2009). Optimization of Dyeing Performance of an Eco Friendly Natural Dye "Vervain Barks" applied to Silk fabrics at different $\mathrm{pH}$ values. RJTA 13(1), 34-45.

[3] Ali, S., Hussain, T., Nawaz, R. (2009). Optimization of alkaline extraction of natural dye from Henna leaves and its dyeing on cotton by exhaust method, $J$ Cleaner Production, 17 (1), 61-66.

[4] Bechtold, T., Turcanu, A., Ganglberger, E., Geisler, S. (2003). Natural Dyes in Modern Textile Dyehouses, Journal of Cleaner Production, vol.11, no 5, pages 499-509.

[5] Bechtoldt, T., Mussak, R., Mahmud-Ali, A., Ganglberger, E., Geissler, S. (2006). Extraction of natural dyes for textile dyeing from coloured plant wastes released from the food and beverage industry, J. Sci. Food Agric., Vol: 86, pages 233-242.
[6] Cardon, D. (2010). Natural Dyes, Our Global Heritage of Colors, Textile Society of America Symposium Proceedings, paper 12, Available on http://digitalcommons. unl.edu/tsaconf/12.

[7] Chandravanski, S., Updhyay, S.K. (2013). Interaction of Natural Dye (Allium cepa) with ionic surfactants, Journal of Chemistry, article ID 686679.

[8] Deo, H.T., Desai, B. K. (1999). Dyeing of cotton and iute with tea as a natural dye, Coloration Technology, vol. 115, no.7, 8, pp.224-227, ISSN 1478-4408.

[9] Devi, M., Ariharan, V.N., Nagendra Prasad P. (2013). Annato: Eco-Friendly and Potential Source for Natural Dye, International Research Journal of Pharmacy, 4, (6), ISSN: 2230-8407.

[10] Garland, C. E. (1993). Color technology in textile chemistry, AATCC, In C. Gultekin (Ed.), pp.107-112.

[11] Ghorpade, B., Darvekar, M., Vankar, P.S. (2000). Ecofriendly cotton dyeing with Sappan wood dye using ultrasound energy, Colourage, 27-30.

[12] Gulrajani, M. L., Deepti, G. (1992). Natural Dyes and Their Applications to Textiles, Department of Textile Technology, Indian Institute of Technology, Delhi, India.

[13] Gulrajani, M. L., Gupta, D. (1992). Natural Dyes and Their Application to Textiles, II New Delhi, India.

[14] Heba, F. M., Gamal, A. M. (2011). Environmental Assessment of Osage orange Extraction and its Dyeing Properties on Protein Fabrics, Part II: Dyeing Properties. J.Environ. Sci. Technol. 4(4): 395-402.

[15] Hemp, Available from http://en.wikipedia.org/wiki/Hemp, accessed 15 August 2014.

[16]Jothi, D. (2008). Extraction of natural dyes from African Marigold Flower (Tagetes Ereectal) for textile coloration, AUTEX Research Journal, vol.8, no.2, pages 49-53.

[17] Khadijah, Q., Heba, M. (2013). Environmental production of fashion colors from natural dyes, academic Journals, International Journal of Physical Sciences, vol.8, (16), pp.670-683, ISSN 1992-1950.

[18] Kubelka, P.I. (1948). New Contribution to the optics of intensity light-scattering materials- Part I. JOSA. 38:448451.

[19] Kumbasar, P. (2011). Natural dyes, Intech, Chapter 3, ISBN: 978-953-307-783-3, http://www.intechopen.com/ books/natural-dyes/dyeing-of-textiles-with-natural-dyes, accessed 17 August 2014.

[20] Leggett, W. F. (1944). Ancient and Medieval Dyes, Brooklyn, NY: Chemical Publishing, Available on www: http://www.epa.gov/guide/history.html, accessed 7 July 2014.

[21] Mirjalili, M., Karinini, L. (2013). Antibacterial dyeing of poliamide using tumeric as a natural dye, Autex Research Journal, vol.13, Issue 2, pages 51-56, ISSN 1470-9589.

[22] Naz, S., Bhattia, I.A., Addel, S. (2011). Dyeing properties of cotton fabric using un-irradiated and gamma irradiated extracts of Eucaliptus camaldulensis bark power,Indian Journal of Fibre\&Textile Research, vol.36, no.2, pp.132136.

[23] Osman, E. M., El-Ebissy, A. A., Michaell, M.N. (2009). Characterization and Evaluation of the Levelness Parameters of Natural Dyes on Natural Fabrics, RJTA 13(2):61-68. 
[24] Prabhu, K. H., Bhute, A. S. (2012). Plant based natural dyes and mordants: A Review, J. Nat. Prod. Plant Resour., vol (2012), 2 pp: (6):649-664.

[25] Rungruangkitkrail, N., Mongkholrattanasit R. (2012). EcoFriendly of Textiles Dyeing and Printing with Natural Dyes, RMUTP International Conference: Textiles \& Fashion, Bangkok, Thailand.

[26] Samanta, A. K., Agarwal, P. (2009). Application of Natural Dyes on Textiles, IJFTR 34, 384-399.

[27] Siva, R. (2007). Status of natural dyes and dye-yielding plants in India, Curr. Sci. 92(7):916-925.
[28] Vankar, P. S. (2000). Chemistry of Natural Dyes, Resonance, vol.5, pp.73-80; Vankar, P. S., Tiwari, V., Ghorpade, B., Natural Dyes: Convention Proceedings, (2001), Indian Institute of Technology, Delhi, India, edited by D. Gupta and M.L. Gulrajani.

[29] Vankar, P. S., Shanker, R., Wijayapala, S. (2009). Dyeing with extract of Allium cepa, Pigment\&Resin Technology, vol.38, iss:4, pp. 242-247.

[30] WHO Quality control guidelines for medicinal plant materials (WHO Geneva) 1998, 1-11, available from http:// whqlibdoc. who.int/publications/1998/9241545100.pdf, accessed 7 July 2014. 